\title{
Back to the Future: Introducing the Journal of Medical Toxicology
}

\author{
Kevin C. Osterhoudt, MD, MSCE, FACMTa, Keith Burkhart, MD, FACMT a
}

a American College of Medical Toxicology, Fairfax, VA

In January, 1998, the American College of Medical Toxicology launched the progressive-minded, Web-based Internet Journal of Medical Toxicology (IJMT). An Internet journal promised many advantages: inexpensive production costs, free and worldwide dissemination, adaptability to a wide range of presentation formats. In 1998, as well as today, we imagined a "paperless" future. We continued to see E-tickets replacing paper airline tickets, cash being replaced by electronic accounts, and news more accessible by the computer screen than by the newspaper.

In our move to a paperless society, prominent scholars such as the National Institutes of Health Director, Elias Zerhouni, have called for mandatory Web-based "open access" to medical journal articles. And it was recently revealed that Internet management giant Google ${ }^{\mathrm{TM}}$ was involved with a project to electronically scan the paper holdings of several major academic libraries. The American College of Medical Toxicology had the foresight to be ahead of its time.

However, during the past few years of paperless progress, we have also seen reason for caution. We have watched as "dotcoms" have come and gone and investors have made and lost fortunes. Computer viruses have become more contagious, and a constant stream of computer health alerts flows in cyberspace. Worldwide terroristic violence has made many of us hold tight on the rapid roller coaster to the future. Indeed, there still seems to be something very reassuring, tangible and real about a paper journal, or a good old-fashioned textbook-the weight and texture in our hands-the ability to lay it upon the coffee table or desk. Many toxicology researchers and academicians still like to think of their hard written work sitting prominently on a wooden, rather than virtual, library shelf.

In 2004 the College convened a focus group of its members to provide some goals in long range planning for the College. One strong recommendation the College received was to develop a print journal for dissemination of medical toxicology research, observation, and opinion. When, in that same year, the journal Veterinary and Human Toxicology ceased publication, an opportunity arose to launch a new journal.

With this issue of the Journal of Medical Toxicology (JMT), the American College of Medical Toxicology is proud to introduce you to its new print journal. The JMT is the official print journal of the American College of Medical Toxicology. It aims to be an international, peer-reviewed journal dedicated to advancing the science and practice of medical toxicology, a medical subspecialty focusing on the diagnosis, management, and prevention of poisoning/toxicity and other adverse health effects resulting from medications, chemicals, occupational and environmental substances, and biological hazards.

The College has chosen to partner with the University of Pennsylvania Press in the production of this journal. The relationship between the American College of Medical Toxicology and the Penn Press is a natural one in many ways. The ACMT and Penn Press are both not-for-profit, and share a common mission in the promotion of research and education. The Penn Press assures low start-up costs for the College, and allows inexpensive subscription rates to both individuals and institutions. Affordable subscriptions should promote increased availability and dissemination of the information found within the journal's pages. And while the publishing experts at Penn Press have considerable experience with typical for-profit medical publishing companies, their friendly team approach plays well with our professional society.

This issue of the JMT blends the past with the future in this "teaser" issue. We are proud to display two original research articles that were the fruits of ACMT-sponsored research grants. Similarly, we are happy to have a provocative original article from our academically productive toxicology colleagues in Australia.

Keywords: societies, medical, periodicals, publishing

Corresponding Author: Kevin C. Osterhoudt, MD, MSCE, The American College of Medical Toxicology, 11240 Waples Mill Road, Suite 200, Fairfax, VA 22030. Email: info@acmt.net 
We have also chosen to reprint a few articles from the screens of the IJMT. Starting in 2006, the Journal will be published quarterly, and will boast several serial features that we hope will be educational and stimulating for those interested in medical toxicology.

The American College of Medical Toxicology encourages you to use the Journal of Medical Toxicology as your venue for publication of your research articles, case reports, scholarly reviews, and opinion. Articles currently published in the IJMT will exist in perpetuity, and the ACMT website will remain a forum for lectures and symposia, interesting graphical presentations, and other alternative media. Since the JMT will be distributed as a member benefit to all ACMT members, your important work will be seen by an important audience. The Journal will strive to quickly make acceptance decisions regarding submitted manuscripts, and to provide top-notch copyediting services. Both the College and the Penn Press have been communicating with representatives of the National Library of Medicine in a confident effort to achieve Medline indexing for all of its articles at the first available opportunity. The growth of the Journal of Medical Toxicology now depends upon your fertile work. Our print journal is a step back in our journey to the future. Share the College's excitement with this new endeavor, and submit your manuscripts! 